\title{
Epstein-Barr Virus and Systemic Lupus Erythematosus
}

\author{
Anette Holck Draborg, Karen Duus, and Gunnar Houen \\ Department of Clinical Biochemistry and Immunology, Statens Serum Institut, Ørestads Boulevard 5, 2300 Copenhagen, Denmark \\ Correspondence should be addressed to Gunnar Houen, gh@ssi.dk
}

Received 20 February 2012; Revised 23 March 2012; Accepted 14 April 2012

Academic Editor: Anne Davidson

Copyright ( 12012 Anette Holck Draborg et al. This is an open access article distributed under the Creative Commons Attribution License, which permits unrestricted use, distribution, and reproduction in any medium, provided the original work is properly cited.

\begin{abstract}
The etiology of SLE is not fully established. SLE is a disease with periods of waning disease activity and intermittent flares. This fits well in theory to a latent virus infection, which occasionally switches to lytic cycle, and EBV infection has for long been suspected to be involved. This paper reviews EBV immunobiology and how this is related to SLE pathogenesis by illustrating uncontrolled reactivation of EBV as a disease mechanism for SLE. Studies on EBV in SLE patients show enlarged viral load, abnormal expression of viral lytic genes, impaired EBV-specific T-cell response, and increased levels of EBV-directed antibodies. These results suggest a role for reactivation of EBV infection in SLE. The increased level of EBV antibodies especially comprises an elevated titre of IgA antibodies, and the total number of EBV-reacting antibody isotypes is also enlarged. As EBV is known to be controlled by cell-mediated immunity, the reduced EBV-specific T-cell response in SLE patients may result in defective control of EBV causing frequent reactivation and expression of lytic cycle antigens. This gives rise to enhanced apoptosis and amplified cellular waste load resulting in activation of an immune response and development of EBV-directed antibodies and autoantibodies to cellular antigens.
\end{abstract}

\section{Systemic Lupus Erythematosus}

Systemic lupus erythematosus (SLE) is a rare autoimmune disease with an incidence of 6-35 new cases per 100.000 per year and typically presents in women (90\% of cases) in the reproductive age [1-3]. The American College of Rheumatology (ACR) updated the clinical criteria for the classification of SLE in 1997, stating that 4 out of 11 criteria should be present consecutively or simultaneously during a period of observation in order to classify SLE (Table 1) [4]. The criteria involve dermatologic symptoms including a butterfly rash on the malar region of the face, discoid rash, photosensitivity, and oral or nasopharyngeal ulcers. Additional criteria comprise arthritis, serositis, renal disorders, and neurologic disorders (including seizures or psychosis). Different hematologic disorders are also included: anemia, leucopenia, lymphocytopenia, and thrombocytopenia. The last two criteria are immunologic disorders including: the presence of antinuclear antibodies (ANAs), which are observed in $80-90 \%$ of SLE patients. Most common are autoantibodies directed against doublestranded DNA (dsDNA) (58-70\% of SLE patients $[2,5])$, but also antibodies to other nuclear components such as histones, Ro52, Ro60, La, and Sm are frequently found [36]. The clinical presentation of SLE is influenced by a variety of factors including ethnicity, gender, age, socioeconomic factors, and age of onset [1]. The typical course of the disease is illustrated by periods of disease flares alternating with waning disease activity, and the typical treatment of SLE consists of immunosuppressive medication, which clinically improves the condition of the patients [7].

The etiology of SLE is believed to be multifactorial with genetic and environmental factors, both contributing to the development of this very complex disease. SLE is concordant in $24 \%$ of monozygotic twins and approximately $2 \%$ of dizygotic twins [8], indicating a genetic contribution. Certain major histocompatibility complex (MHC) II alleles, including HLA-DR2 and HLA-DR3, have been indicated to serve as risk factors in the development of SLE [5], and various HLA-DQ and HLA-DR alleles have been shown to be associated with the production of specific autoantibodies and other clinical manifestations of SLE [5]. Numerous other genes have been shown to be associated with the SLE 
TABLe 1: Symptoms and clinical manifestations of SLE* $[3,4,6]$ and IM [29].

\begin{tabular}{|c|c|}
\hline SLE & IM \\
\hline Malar rash & Skin rash \\
\hline Discoid rash & Palatal exanthema \\
\hline \multicolumn{2}{|l|}{ Photosensitivity } \\
\hline Oral/nasopharyngeal ulcers & Pharyngitis \\
\hline Arthritis & Arthralgias \\
\hline \multicolumn{2}{|l|}{ Serositis } \\
\hline Renal disorders & Renal disorders \\
\hline \multicolumn{2}{|l|}{ Hematologic disorders } \\
\hline Anemia & Anemia \\
\hline Leucopenia & Granulocytopenia \\
\hline \multicolumn{2}{|l|}{ Lymphocytopenia } \\
\hline Thrombocytopenia & Thrombocytopenia \\
\hline Immunological disorders & Lymphoadenopathy \\
\hline ANAs & ANAs \\
\hline Anti-dsDNA & Anti-DNA \\
\hline \multicolumn{2}{|l|}{ Anti-Sm } \\
\hline Anti-histone & Anti-histone \\
\hline Anti-ribonucleoprotein & Anti-ribonucleoprotein \\
\hline Rheumafactor & Rheumafactor \\
\hline \multirow[t]{2}{*}{$\begin{array}{l}\text { Neurologic disorders } \\
\text { (seizures/psychosis) }\end{array}$} & $\begin{array}{l}\text { Neurological disorders } \\
\text { (encephalitis/meningitis) }\end{array}$ \\
\hline & Headaches \\
\hline Fatigue & Fatigue \\
\hline Muscle aches & Muscle aches \\
\hline Low-grade fever & Fever \\
\hline \multirow[t]{3}{*}{ Loss of appetite } & Loss of appetite \\
\hline & Malaise \\
\hline & Hepatosplenomegaly \\
\hline
\end{tabular}

* ACR criteria highlighted in bold.

pathogenesis especially components of interferon pathways (e.g., IRF5, STAT4, and SPP1), which probably reflects general intrinsic immune deficiencies in SLE patients $[9,10]$.

Impaired T-cell proliferation, and abnormal cytokine production has also been demonstrated to play a role in SLE pathogenesis [11]. A T helper $1 / \mathrm{T}$ helper 2 cytokine imbalance is observed in SLE patients. An enhanced T helper 17 cell response has also been detected and correlated with disease activity in SLE patients, which suggests a role for interleukin-17 (IL-17) in the pathogenesis of SLE $[12,13]$.

Another risk factor for developing SLE is deficiencies in the classical complement pathway, especially $\mathrm{Clq}$ (93\%) and C4 $(75 \%)$ deficiency. C1q deficiency may be inherited or acquired as a result of the production of $\mathrm{Clq}$ autoantibodies, which can be detected in some SLE patients. This results in decreased clearance of apoptotic materials leading to accumulation of apoptotic blebs [14-17]. Nuclear autoantigens are clustered at the surface of these blebs. As they are recognized by the immune system as "nonself," they may initiate autoimmune responses [18]. This gives rise to the production of autoantibodies directed against conserved cellular components. The production of autoantibodies results in the formation of circulating immune complexes. When the concentration and size of these complexes reach a critical level, they may deposit in the subendothelium inciting inflammation and tissue damage $[16,19]$.

Environmental risk factors for SLE development are ultraviolet radiation and certain drugs and chemicals [2123], and infections are known to be major environmental factors. Especially Epstein-Barr virus (EBV) infection has been shown to be highly associated with the development of SLE, as presented in the following sections.

\section{Epstein-Barr Virus Infection}

EBV, also known as human herpesvirus 4 (HHV4), is comprised of a $172 \mathrm{~kb}$ linear dsDNA genome inside an envelopeenclosed icosahedral capsid (Figure 1). EBV is a ubiquitous infectious agent, latently infecting approximately $95 \%$ of the world's population [24]. It is transmitted via saliva and replicates initially at mucosal surfaces in oropharyngeal and nasopharyngeal epithelial cells, especially in the tonsillar area. Next, the virus enters the underlying tissues and infects resting $B$ cells via binding of its viral envelope glycoprotein 350 (gp350) to the B-cell type 2 complement receptor (CD21) $[25,26]$.

Central to the understanding of EBV's disease biology is the ability of the virus to shift between an active lytic cycle and a latent state, from which the virus occasionally reactivates.

Primary EBV infection during childhood is asymptomatic, but infection in adolescence causes infectious mononucleosis (IM) in $30-70 \%$ of cases, where the virus infects up to $20 \%$ of the B cells in the body [27, 28]. The reason for the age-related difference in disease is unknown. The most common symptoms and clinical manifestations of IM are skin rash, palatal exanthema, arthralgias, renal disorders, anemia, granulocytopenia, thrombocytopenia, pharyngitis, lymphoadenopathy, hepatosplenomegaly, fatigue, muscle aches, fever, loss of appetite, headaches, and malaise. Furthermore, the central nervous system can be involved, including development of encephalitis or meningitis (Table 1) [29].

Many studies link EBV infection with various autoimmune diseases (e.g., SLE and multiple sclerosis [30-35]) and some cancers, including lymphoid malignancies (e.g., Burkitt's lymphoma [36]) and epithelial cell malignancies (e.g., nasopharyngeal carcinoma [37]). Several cutaneous manifestations have also been associated with EBV infection including hydroa vacciniforme, a photosensitivity dermatosis of childhood mediated by infiltrations of EBV-specific $\mathrm{CD}^{+}$cytotoxic T cells in the skin [38].

2.1. EBV Lytic Cycle. During the primary EBV infection, the virus is in its lytic cycle of existence. The early lytic genes, $B Z L F-1$ and BRLF-1, encoding two transcription factors, are essential for the induction of the lytic replication cycle of EBV and also in the reduction of promoter activity in the 


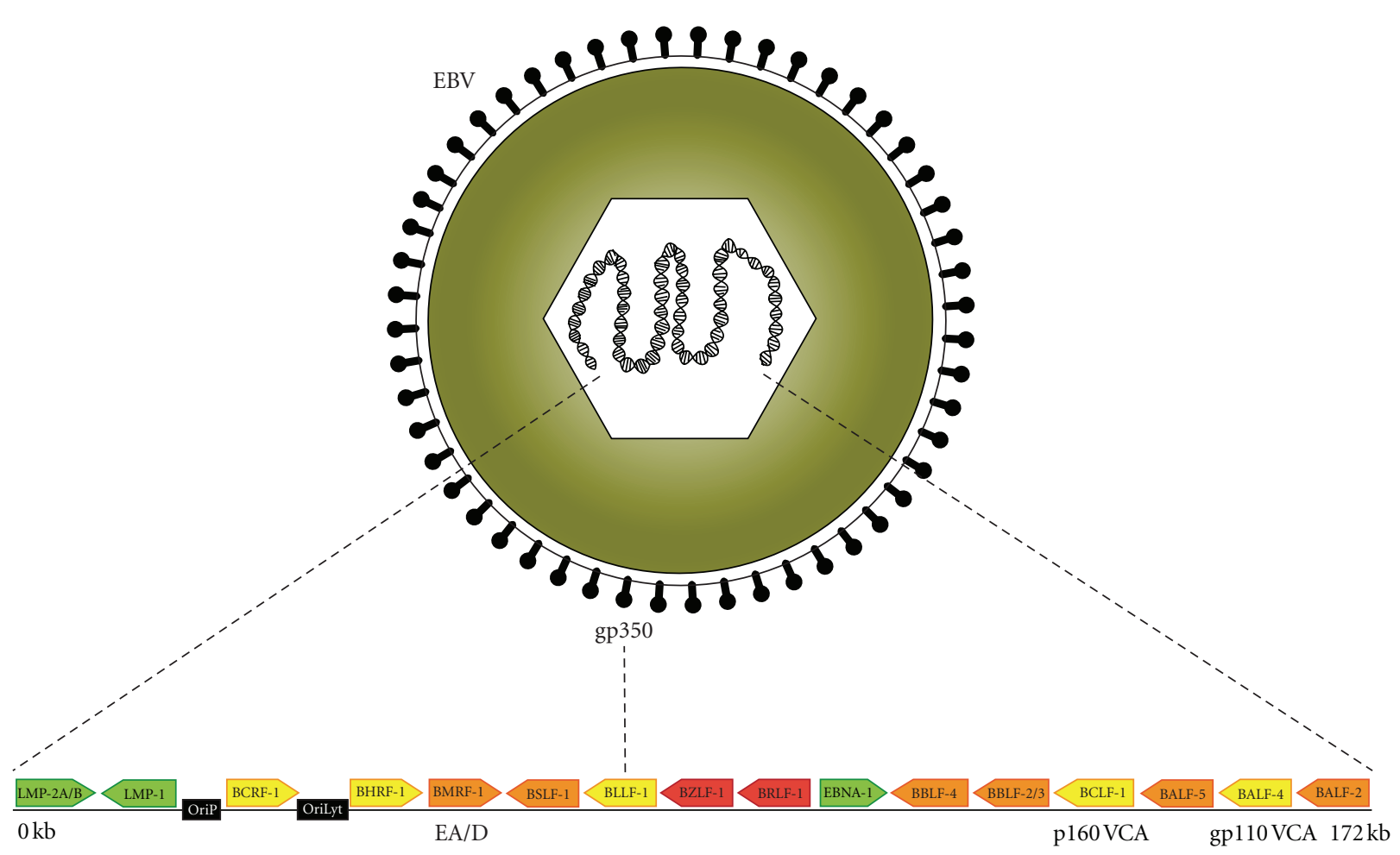

FIGURE 1: EBV structure and partial map of the genome. The EBV virion comprises a $172 \mathrm{~kb}$ linear dsDNA genome inside an icosahedral capsid enclosed by an envelope with viral glycoproteins (gp350) utilized for infection of B cells. The positions of the origins of latent and lytic replication of the viral genome, OriP and OriLyt, respectively, are illustrated in black boxes in the EBV genome map. Selected genes and their relative placement are shown as arrows pointed in the direction of translation [20]. In the latent state, only a few antigens are expressed including EBNA-1, LMP-1, and -2A/B (shown in green). Lytic replication begins with induction of the two early transcription factors (shown in red), which activate early viral promoters generating the initiation complex at OriLyt consisting of 6 viral gene products (illustrated in orange). During lytic cycle, various lytic antigens are expressed (shown in yellow) [20]. Gene products of BMRF-1, BCLF-1, and BALF-4 are depicted as EA/D, p160 VCA, and gp110 VCA, respectively.

latent state of infection $[39,40]$. They activate the early viral promoters required for generation of the initiation complex at the lytic origin of viral replication, oriLyt, consisting of 6 viral gene products. The 6 viral genes are BALF-5, encoding the viral DNA polymerase, BMRF-1, encoding Epstein-Barr virus diffuse early antigen (EBV-EA/D) [41-45], which is the viral DNA polymerase accessory protein, $B A L F-2$, encoding a single-stranded DNA-binding protein, BSLF-1 and BBLF4 , encoding the primase and the helicase, respectively, and BBLF2/3, which encodes the helicase-primase-associated protein [46-51]. The gathering of the initiation complex and the binding of the gene product of BZLF-1 to oriLyt result in lytic replication of the virus.

During lytic cycle, the viral DNA is replicated by a mechanism, where the majority of the 90-100 viral genes are expressed [48]. Multiple rounds of replication are initiated within oriLyt, resulting in viral gene expression and viral genome replication with a 100 - to 1000 -fold amplification $[26,50]$. This gives rise to the shedding of infectious virus into saliva that can infect other B cells and epithelial cells and also be transmitted to a new host [52].

Several lytic cycle antigens expressed during the lytic cycle of infection are involved in immune evasion. These include the BCRF-1 gene encoding a viral IL-10 homologue and $B H R F-1$ encoding restricted early antigen (EA/R), a viral Bcl-2 homologue. Like human IL-10, viral IL-10 inhibits the synthesis of interferon- $\gamma($ IFN- $\gamma)$ and suppresses CD8 ${ }^{+}$ cytotoxic T-cell responses and upregulation of MHC I expression [53]. EA/R protects both infected B cells and epithelial cells from apoptosis [54].

Another EBV lytic cycle antigen, EBV-EA/D, is localized both in the cytoplasm and in the nucleus of infected cells, where it colocalizes with the viral DNA polymerase. EBVEA/D binds dsDNA without sequence specificity and is a part of the EBV DNA-binding complex together with the viral DNA polymerase. It is essential for the polymerase to replicate the viral genome, and EBV-EA/D is therefore termed the EBV DNA polymerase accessory protein [55-58]. EBV-EA/D is also demonstrated to be widely distributed on the newly synthesized EBV genome during lytic replication and is therefore suggested to stabilize the newly synthesized viral DNA [59].

In addition, EBV-EA/D has been shown to have transcription factor activity, inducing activation of several promoters downstream of the oriLyt component, which is required for viral lytic replication $[45,55]$. Studies have proposed that EBV-EA/D somehow functions as a coactivator for the BZLF-1 gene product, improving its transactivation 
of both the BALF-2 gene promoter [60] and the BHLF-1 gene promoter [44]. Different sites of the EBV-EA/D protein have been associated with its different functions. Amino acids 378-404 are required for its transactivator functions [61], and amino acids 194-238 are necessary for stimulation of the viral DNA polymerase [62].

Later in the lytic cycle of infection, the late lytic viral proteins are synthesized: EBV viral capsid antigen (EBVVCA) and membrane antigen (MA). EBV-VCA is a protein composed of a $110 \mathrm{kDa}$ glycoprotein (gp110) and a $160 \mathrm{kDa}$ protein (p160) encoded by BALF-4 and BCLF-1, respectively. gp110 is involved in virus maturation and improves the efficiency of the virus to infect B cells and epithelial cells [63], whereas p160 is essential for the assembly of the viral capsid [64].

2.2. Latent State. After primary infection, EBV usually enters the latent state as a consequence of the host's immune response. The result of primary EBV infection is numerous EBV-infected B cells, which have induced continuous proliferation and prevented apoptosis resulting in differentiation into immortalized resting memory $\mathrm{B}$ cells. These can exit the tonsils and enter the peripheral circulation, and they can persist for life in the host [52]. The EBV genomic DNA will undergo circularization and thus consists of a closed circular plasmid that behaves as the host's chromosomal DNA, which results in severely restricted expression of viral genes. Based on these and other immune evasion mechanisms, the virus becomes undetectable by the immune system $[25,26]$.

In the latent state of infection, nearly all of the approximately 80 viral promoters are silenced, and a maximum of 9 genes are expressed. These include the nuclear antigens (EBNA-1, -2, -3A, -3B, and -3C), the leader protein (LP), and the latent membrane proteins (LMP-1, $-2 \mathrm{~A}$, and $-2 \mathrm{~B}$ ) $[52,66]$. LMP-1 and LMP-2A both act as survival signals of the infected B cell. LMP-1 serves as the signal that normally comes from the CD40 signal transduction pathway initiated by $\mathrm{CD}^{+}{ }^{+}$T-cell help, and LMP-2A provides the signal normally generated by antigen binding of the B-cell receptor. Thus, these two latent EBV antigens rescue the infected B cells from apoptosis $[66,67]$.

EBNA-2 is known to be the most important transcription factor and controls the expression of all other latent viral genes. It blocks lytic replication in the majority of EBVinfected cells, ensuring the presence of latently infected $\mathrm{B}$ cells and thereby obstructing EBV elimination by the immune response of the host [52]. EBNA-1 is the only viral antigen required for maintenance of the viral genome as it acts as a replication factor during latent infection, where the EBV genomic DNA only is replicated once every cell cycle $[26,52]$. When resting memory B cells are latently infected for a longer period of time, EBV only expresses EBNA-1. The EBNA-1 protein contains a glycine and alanine repeat domain, which ensures that the protein is not degraded by the proteasome of the host. Therefore, no EBNA-1 peptides are presented at the surface of the infected $\mathrm{B}$ cells, and the virus is thus hidden from the immune system $[25,68]$.
2.3. Reactivation and Switch to the Lytic Cycle. Occasionally, EBV can reactivate and switch back to the lytic cycle. The triggers for EBV reactivation are unknown. However, differentiation of infected $B$ cells into plasma cells might trigger the activation of the promoter for early lytic genes, which eventually will result in replication and switch to lytic cycle $[25,52,69]$. Yet, the signals and timing involved in this process are unknown and must be a dynamic correlation between the host's immune response towards EBV and the infection state. It is established that activation of the lytic program happens in latently infected memory B cells passing through the lymphoid tissue associated with the pharynx mucosa [26]. Because of this ability of the virus to reactivate, it serves as a constant antigenic challenge to the host.

2.4. Response from the Immune System to EBV. Both latent and lytic EBV antigens are potent immunogens, and a vigorous immune response is initiated during EBV infection. This response involves all parts of the immune system and will control, but not eliminate, the infection. The expansion of EBV-infected B cells during lytic cycle is especially controlled by $\mathrm{CD}^{+}$cytotoxic $\mathrm{T}$ cells, which kill infected $\mathrm{B}$ cells and also induce the latent state in remaining EBV-infected B cells [70]. Cell-mediated immunity is also crucial in preventing the latent infection from entering lytic replication [25]. IFN$\gamma$ is suggested to be an important mediator of the immune response against EBV, as the level of IFN- $\gamma$ is highly increased in patients with IM [71]. The clinical symptoms do not disappear until the amounts of both infected B cells in lytic cycle and of activated $\mathrm{T}$ cells are reduced, which occurs after approximately 4 weeks for normal immunocompetent individuals [25]. The $\mathrm{CD}^{+}$cytotoxic T-cell response toward EBV accounts for the cutaneous symptoms associated with EBV infection (Table 1) [72].

A humoral immune response is also initiated during EBV infection, and EBV-infected individuals have distinct serologic profiles during the latent and acute phases. In early stages of the primary infection, antibodies toward EBV-VCA and EBV-EA/D are generated, whereas EBNA1 antibodies develop later. EBV-VCA IgM antibodies are diagnostic for recent active infection [73]. Antibodies of the IgG isotype to EBV-VCA and EBNA-1 will persist throughout life [74]. EBV-EA/D-directed antibodies are known as a strong indication of lytic replication of the virus [74]. Serum IgA antibodies toward the BZLF-1 gene product and EBV$\mathrm{EA} / \mathrm{D}$ have been shown to be produced during active disease and are suggested to be stimulated by EBV replication in mucosal sites [75]. The antibodies produced against EBV antigens counteract the viral infection mainly by antibodydependent cell-mediated cytotoxicity [72].

\section{Association between EBV Infection and SLE}

Many studies have revealed a connection between SLE and EBV infection. Essentially all adult SLE patients are infected with EBV (99.5\%) [24]. However, the statistical significance of this finding is reduced by the large proportion of healthy adults infected as well (95\%). In young people below the 
TABLE 2: EBV-EA/D antibodies in SLE patients and healthy controls [65].

\begin{tabular}{lcc}
\hline $\begin{array}{l}\text { No. of antibody isotypes } \\
\text { (IgG, IgA, IgM) }\end{array}$ & \% SLE patients & \% Healthy controls \\
\hline 0 & $12 \%$ & $65 \%$ \\
1 & $23 \%$ & $25 \%$ \\
2 & $28 \%$ & $10 \%$ \\
3 & $37 \%$ & $0 \%$ \\
\hline
\end{tabular}

age of 20 years, the difference between SLE patients and healthy controls is more evident, as the prevalence of EBV infection in the control population is lower, with only $70 \%$ being infected, while essentially all pediatric SLE patients are infected with EBV (99.6\%) [76, 77].

As demonstrated in Table 1, SLE and EBV-induced IM are known to have similar symptoms and clinical manifestations, indicating an association. Most interesting, presence of rheumafactor and autoantibodies against cellular components like DNA, histones, and ribonucleoproteins is found in IM patients as well as in SLE patients [78, 79]. EBV infection may somehow result in both diseases according to the genetic predisposition and the immune response against EBV in the individual.

SLE patients have been shown to have at least a 10fold increased frequency of EBV-infected peripheral B cells compared to healthy controls. This increase is associated with increased disease activity in SLE patients and is independent of intake of immunosuppressive medication [31]. In addition, an abnormally high viral load in the peripheral blood mononuclear cells (PBMCs) has been demonstrated in SLE patients compared to healthy controls in several studies [33$35,80]$. Kang et al. found, by the use of real-time quantitative PCR, a 40-fold increase of EBV load when comparing SLE patients to healthy controls [33], and Moon et al. found at least a 15-fold increase of EBV load in SLE patients [34]. Furthermore, $\mathrm{Lu}$ et al. found a significantly elevated level of EBV DNA in serum from $42 \%$ of the examined SLE patients compared to only $3 \%$ of the healthy controls [80]. These findings suggest EBV active lytic cycle with profound viral replication in SLE patients. Thus, it may be indicated that reactivation of EBV is associated with the development of SLE.

Studies on normal immunocompetent carriers of EBV demonstrate that they usually show little or no mRNA expression by EBV. Gross et al. have demonstrated that SLE patients have abnormal expression of 4 viral mRNAs: BZLF1, LMP-1, LMP-2, and EBNA-1 in their PBMCs [31]. The measured expression levels of mRNAs were often higher than in individuals with IM indicating very active virus. BZLF-1 is one of the early lytic genes, facilitating the initiation of the lytic replication of the virus, and expression of this mRNA in SLE patients clearly indicates reactivation of the virus. In addition, an abnormal latency state is indicated in the SLE patients by the increased expression of the three latent state mRNAs. The enhanced expression of LMP mRNAs might result in improved survival of EBV-infected B cells, as the encoded antigens serve as survival signals that normally comes from the CD40 signal pathway and by antigen binding to the B-cell receptor $[66,67]$.

Also, Poole et al. measured the levels of EBV mRNA in PBMCs from SLE patients and healthy controls infected with EBV [81]. They found a 3.2-fold increase in the $B L L F-1$ mRNA encoding gp350, which is essential for the binding and infection of new B cells. Also, the BCRF-1, EBNA-1, and LMP-2 mRNAs were increased 1.7-fold in SLE patients compared to healthy controls. These results suggest that the EBV infection is active and harder to control in the SLE patients.

Serologic evidence of a connection between EBV infection and SLE development has been illustrated several times by examining the presence of antibodies to EBNA-1, EBVVCA, and EBV-EA in sera from SLE patients. Studies on antibodies to EBNA-1 and EBV-VCA are contradictive. Most studies show no difference in the prevalence of $\operatorname{IgG}$ and IgM antibodies to either EBNA-1 or EBV-VCA between SLE patients and healthy controls [82-85]. However, studies on pediatric SLE patients and one study on adults show that only two-thirds of healthy controls compared to all SLE patients are seropositive for these antibodies [24, 76, 77]. Furthermore, an elevated amount of both EBNA-1 and EBVVCA IgA antibodies has been detected in SLE patients [80, $83,86,87]$.

In addition, elevated titers of IgG antibodies to early lytic antigens including EBV-EA/D, EBV-EA/R, and the BALF2 gene product have been found in approximately half of SLE patients compared to only $8-17 \%$ of healthy controls by several research groups $[82,84,85,88,89]$. Most interesting, elevated levels of IgA antibodies to these antigens have also been found in SLE patients, characteristic of epithelial infection. Lau et al. demonstrated that 15\% of SLE patients compared to none of the healthy controls were positive for EBV-EA IgA antibodies by immunofluorescence [90], and Draborg et al. found a positive rate of IgA EBV-EA/D antibodies of 58\% regarding SLE patients, whereas none of the serum samples from healthy controls showed IgA antibody binding to EBV-EA/D [65]. Furthermore, when compiling the positivity for EBV-EA/D-reacting antibody isotypes (IgG, $\operatorname{IgM}$, and IgA) for each individual, $65 \%$ of the SLE patients were positive for two or three isotypes. None of the healthy controls were positive for three isotypes, and only $10 \%$ were positive for two isotypes, whereas the majority (65\%) had no antibodies against EBV-EA/D (Table 2) [65]. These results could not be explained by intake of immunosuppressive medication, indicating that the antibodies do not occur upon reactivation of EBV due to an iatrogenically suppressed 


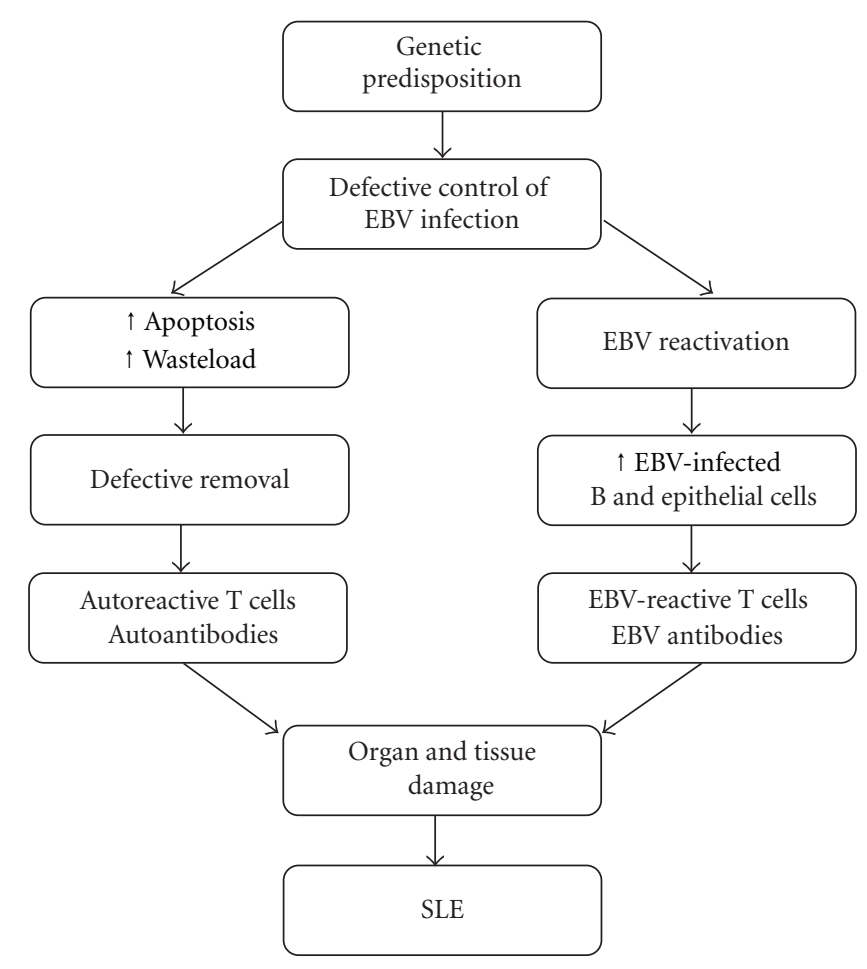

FIGURE 2: Hypothesis of development of SLE from EBV infection. Genetic insufficiencies may result in poor control and thereby more frequent reactivation of the latent EBV infection. The increased number of EBV-infected cells will, upon apoptosis, initiate an innate and adaptive immune response against the released cellular antigens and EBV antigens due to defective removal of waste products. This will result in production of autoantibodies and EBV antibodies as an attempt to control the virus-induced inflammation. Furthermore, activation of both autoreactive and EBV-reactive T cells will occur. The response from the immune system cause organ and tissue damage leading to development of SLE.

immune system. Presumably, the results of high prevalence of IgA antibodies against EBV reflect the host's attempt to control reactivation or reinfection of EBV in epithelial cells. Additionally, the presence of multiple EBV-EA/D antibody isotypes indicates a more disseminated EBV infection in SLE patients than in healthy controls.

The constant attempts of the host's immune system to control the virus apparently lead to attack on cells expressing EBV-EA/D, resulting in killing of infected cells before assembly of mature EBV particles. This results in release of EBV-EA/D (presumably bound to dsDNA) and intracellular antigens (including those involved in EBV replication and protein synthesis). Since this occurs both in B cells and epithelial cells, the antibody response involves both IgG and IgA to EBV-EA/D and autoantigens (e.g., dsDNA and ribonucleoproteins), depending on the individuals infection distribution and immune system.

Actually, IgA deficiency has been shown to be a risk factor for development of SLE as it results in frequent infections, and approximately $6 \%$ of SLE patients have been shown to suffer from IgA deficiency [91, 92]. It could be speculated that defects in controlling EBV infection result in SLE development in different ways. Presumably, some individuals develop SLE due to lack of production of IgA antibodies to counteract an epithelial EBV reactivation. Other individuals are not able to control EBV infection as a result of other immune defects and therefore attempt to control EBV with production of IgA antibodies against EBV lytic cycle antigens (especially EBV-EA/D).

An additional mechanism by which EBV can contribute to development of SLE is molecular mimicry. EBNA-1 has been shown to cross-react with SLE-associated autoantigens resulting in cross-reactive antibodies followed by epitope spreading, which eventually can result in development of SLE [93-95].

The reduced EBV-specific T-cell reactivity observed in SLE patients is possibly a consequence of defective EBVspecific T cells, which indicate poor control of EBV infection. Actually, the defective control of the virus has been demonstrated to involve an impaired EBV-specific T-cell response in SLE patients $[33,96]$. Studies conducted by Berner et al. on EBV-specific T cells in SLE patients showed a tendency of an increased frequency of $\mathrm{CD}^{+} \mathrm{T}$ cells toward a specific epitope of the lytic cycle BMLF1 protein. These results were obtained by analysis of PBMCs using MHC I tetramers. Using an ELISPOT assay, the EBV-reactive $\mathrm{CD}^{+} \mathrm{T}$ cells were found to be incapable of producing IFN- $\gamma$ upon stimulation [96]. This indicates that the EBV-specific CD8 ${ }^{+} \mathrm{T}$ cells of SLE patients may have a defect in their ability to become activated upon stimulation and will thereby produce poor effector responses. In addition, Kang et al. found a tendency of SLE patients to have a decreased amount of EBV-specific 
$\mathrm{CD}^{+}$cytotoxic $\mathrm{T}$ cells producing IFN $-\gamma$, when samples of whole blood were stimulated with EBV [33]. Simultaneously, they showed a significantly increased frequency of EBVspecific $\mathrm{CD}^{+} \mathrm{T}$ cells producing IFN- $\gamma$ in SLE patients when stimulated [33]. These results suggest that the impaired EBVspecific T-cell response in SLE patients comprises a defect in EBV-specific $\mathrm{CD}^{+}$T-cell cytotoxicity and a compensatory increased frequency of EBV-specific $\mathrm{CD} 4^{+} \mathrm{T}$ cells.

The above-mentioned associations between active and uncontrolled EBV infection and SLE indicate that EBV and possibly also other viruses have a pathogenic role in the development of SLE. Other viruses besides EBV have been suggested to be associated with SLE including cytomegalovirus [97], parvovirus B19 [98], hepatitis B [98], and human endogenous retroviruses [99]. Overall, infections are presumably involved in SLE induction, and SLE patients have an increased susceptibility to many kinds of infections [100]. These findings are related to the intrinsic immune defects found in SLE patients.

\section{Conclusion}

The much investigated association between EBV infection and the development of SLE indicates genetic and/or acquired difficulties with suppressing the infection and keeping EBV in its latent state. This is demonstrated by defective EBV-specific $\mathrm{T}$ cells, an abnormally high viral load, expression of viral genes, and high levels of EBV IgA antibodies in SLE patients.

Presently, the major genetic predisposing factors are deficiencies in components of the classical complement pathway [17], certain MHC alleles [5], components of IFN pathways, and other immune-regulatory pathways [9, 10, 91]. Acquired antibodies to C1q may also contribute to disease development. These factors may contribute in different ways. Genetically determined immune deficiencies and the presence of particular MHC alleles may first of all limit the ability to control EBV infection and reactivation, and complement deficiencies impair the removal of necrotic and apoptotic cell debris [14-16, 18]. This theory covers many aspects of SLE, but does not explain the female preponderance. Presumably, the solution to this problem shall be found in genetically determined immune system differences or in pregnancy/maternity-related influences on the immune system.

As demonstrated in Figure 2, it is hypothesized that lack of control of EBV infection could result in more widespread latent infection and more frequent reactivation. This entails increased numbers of EBV-infected B cells and epithelial cells and may lead to enhanced apoptosis of cells and amplified cellular waste load. An immune response is therefore initiated with development of autoantibodies against cell components. Lack of control of EBV infection may thus be a contributing factor to development of SLE. $\mathrm{EBV}$ reactivation may also give rise to release of EBV lytic cycle antigens resulting in the demonstrated production of EBV-directed antibodies reflecting the hosts attempt to control the reactivation.
Clinically, the constant interplay between EBV reactivation, reinfection, and the host's immune response results in individual disease patterns and clinical presentations, spanning from initial mild symptoms to ultimate classification as SLE as more and more ACR criteria are fulfilled.

In conclusion, the demonstrated associations between EBV and SLE suggest that infection with and reactivation of EBV has a pathogenic role as an environmental trigger inducing or promoting the development of SLE in genetically predisposed individuals.

$\begin{array}{ll}\text { Abbreviations } \\ \text { ACR: } & \text { American College of Rheumatology } \\ \text { ANA: } & \text { Antinuclear antibody } \\ \text { dsDNA: } & \text { Double-stranded DNA } \\ \text { EA/D: } & \text { Diffuse early antigen } \\ \text { EA/R: } & \text { Restricted early antigen } \\ \text { EBNA: } & \text { Epstein-Barr nuclear antigen } \\ \text { EBV: } & \text { Epstein-Barr virus } \\ \text { gp: } & \text { Glycoprotein } \\ \text { HHV4: } & \text { Human herpesvirus } 4 \\ \text { IFN: } & \text { Interferon } \\ \text { IL: } & \text { Interleukin } \\ \text { IM: } & \text { Infectious mononucleosis } \\ \text { LMP: } & \text { Latent membrane protein } \\ \text { LP: } & \text { Leader protein } \\ \text { MA: } & \text { Membrane antigen } \\ \text { MHC: } & \text { Major histocompatibility complex } \\ \text { PBMC: } & \text { Peripheral blood mononuclear cell } \\ \text { SLE: } & \text { Systemic lupus erythematosus } \\ \text { VCA: } & \text { Viral capsid antigen. }\end{array}$

\section{References}

[1] G. J. Pons-Estel, G. S. Alarcón, L. Scofield, L. Reinlib, and G. S. Cooper, "Understanding the epidemiology and progression of systemic lupus erythematosus," Seminars in Arthritis and Rheumatism, vol. 39, no. 4, pp. 257-268, 2010.

[2] A. Rahman and D. A. Isenberg, "Systemic lupus erythematosus," New England Journal of Medicine, vol. 358, no. 9, pp. 929-939, 2008.

[3] P. P. Smith and C. Gordon, "Systemic lupus erythematosus: clinical presentations," Autoimmunity Reviews, vol. 10, no. 1, pp. 43-45, 2010.

[4] M. C. Hochberg, "Updating the American College of Rheumatology revised criteria for the classification of systemic lupus erythematosus," Arthritis and rheumatism, vol. 40, no. 9, p. 1725, 1997.

[5] B. Namjou, J. Kilpatrick, and J. B. Harley, "Genetics of clinical expression in SLE," Autoimmunity, vol. 40, no. 8, pp. 602612, 2007.

[6] C. A. Von Muhlen and E. M. Tan, "Autoantibodies in the diagnosis of systemic rheumatic diseases," Seminars in Arthritis and Rheumatism, vol. 24, no. 5, pp. 323-358, 1995.

[7] M. Dall'Era and E. F. Chakravarty, "Treatment of mild, moderate, and severe lupus erythematosus: focus on new therapies," Current Rheumatology Reports, vol. 13, no. 4, pp. 308-316, 2011.

[8] D. Deapen, A. Escalante, L. Weinrib et al., "A revised estimate of twin concordance in systemic lupus erythematosus," Arthritis and Rheumatism, vol. 35, no. 3, pp. 311-318, 1992. 
[9] A. L. Sestak, B. G. Fürnrohr, J. B. Harley, J. T. Merrill, and B. Namjou, "The genetics of systemic lupus erythematosus and implications for targeted therapy," Annals of the Rheumatic Diseases, vol. 70, no. 1, pp. i37-i43, 2011.

[10] P. S. Ramos, A. H. Williams, J. T. Ziegler et al., "Genetic analyses of interferon pathway-related genes reveal multiple new loci associated with systemic lupus erythematosus," Arthritis and Rheumatism, vol. 63, no. 7, pp. 2049-2057, 2011.

[11] G. M. Kammer, A. Perl, B. C. Richardson, and G. C. Tsokos, "Review: abnormal $\mathrm{T}$ cell signal transduction in systemic lupus erythematosus," Arthritis and Rheumatism, vol. 46, no. 5, pp. 1139-1154, 2002.

[12] K. Shah, W. W. Lee, S. H. Lee et al., "Dysregulated balance of Th17 and Th1 cells in systemic lupus erythematosus," Arthritis Research and Therapy, vol. 12, no. 2, article no. R53, 2010.

[13] G. C. Tsokos, "Systemic lupus erythematosus," New England Journal of Medicine, vol. 365, no. 22, pp. 2110-2121, 2011.

[14] U. S. Gaipl, L. E. Munoz, G. Grossmayer et al., "Clearance deficiency and systemic lupus erythematosus (SLE)," Journal of Autoimmunity, vol. 28, no. 2-3, pp. 114-121, 2007.

[15] L. E. Munoz, U. S. Gaipl, S. Franz et al., "SLE-a disease of clearance deficiency?” Rheumatology, vol. 44, no. 9, pp. 11011107, 2005.

[16] L. E. Muñoz, C. Janko, C. Schulze et al., "Autoimmunity and chronic inflammation-two clearance-related steps in the etiopathogenesis of SLE," Autoimmunity Reviews, vol. 10, no. 1, pp. 38-42, 2010.

[17] L. Truedsson, A. A. Bengtsson, and G. Sturfelt, "Complement deficiencies and systemic lupus erythematosus," Autoimmunity, vol. 40, no. 8, pp. 560-566, 2007.

[18] L. E. Munoz, C. Van Bavel, S. Franz, J. Berden, M. Herrmann, and J. Van Der Vlag, "Apoptosis in the pathogenesis of systemic lupus erythematosus," Lupus, vol. 17, no. 5, pp. 371375, 2008.

[19] L. E. Mũoz, K. Lauber, M. Schiller, A. A. Manfredi, and M. Herrmann, "The role of defective clearance of apoptotic cells in systemic autoimmunity," Nature Reviews Rheumatology, vol. 6, no. 5, pp. 280-289, 2010.

[20] P. J. Farrell, "Epstein-Barr virus. The B95-8 strain map," Methods in Molecular Biology, vol. 174, pp. 3-12, 2001.

[21] P. Sarzi-Puttini, F. Atzeni, L. Iaccarino, and A. Doria, "Environment and systemic lupus erythematosus: an overview," Autoimmunity, vol. 38, no. 7, pp. 465-472, 2005.

[22] P. Sarzi-Puttini, F. Atzeni, F. Capsoni, E. Lubrano, and A. Doria, "Drug-induced lupus erythematosus," Autoimmunity, vol. 38, no. 7, pp. 507-518, 2005.

[23] C. D. Vedove, M. Del Giglio, D. Schena, and G. Girolomoni, "Drug-induced lupus erythematosus," Archives of Dermatological Research, vol. 301, no. 1, pp. 99-105, 2009.

[24] J. A. James, B. R. Neas, K. L. Moser et al., "Systemic lupus erythematosus in adults is associated with previous EpsteinBarr virus exposure," Arthritis and Rheumatism, vol. 44, no. 5, pp. 1122-1126, 2001.

[25] H. H. Niller, H. Wolf, and J. Minarovits, "Regulation and dysregulation of Epstein-Barr virus latency: implications for the development of autoimmune diseases," Autoimmunity, vol. 41, no. 4, pp. 298-328, 2008.

[26] T. Tsurumi, M. Fujita, and A. Kudoh, "Latent and lytic Epstein-Barr virus replication strategies," Reviews in Medical Virology, vol. 15, no. 1, pp. 3-15, 2005.
[27] P. G. Auwaerter, "Infectious mononucleosis in middle age," Journal of the American Medical Association, vol. 281, no. 5, pp. 454-459, 1999.

[28] P. Tattevin, Y. Le Tulzo, S. Minjolle et al., "Increasing incidence of severe Epstein-Barr virus-related infectious mononucleosis: surveillance study," Journal of Clinical Microbiology, vol. 44, no. 5, pp. 1873-1874, 2006.

[29] S. E. Straus, J. I. Cohen, G. Tosato, and J. Meier, "Epstein-Barr virus infections: biology, pathogenesis, and management," Annals of Internal Medicine, vol. 118, no. 1, pp. 45-58, 1993.

[30] B. A. Bagert, "Epstein-Barr virus in multiple sclerosis," Current Neurology and Neuroscience Reports, vol. 9, no. 5, pp. 405-410, 2009.

[31] A. J. Gross, D. Hochberg, W. M. Rand, and D. A. ThorleyLawson, "EBV and systemic lupus erythematosus: a new perspective," Journal of Immunology, vol. 174, no. 11, pp. 6599-6607, 2005.

[32] S. Haahr and P. Höllsberg, "Multiple sclerosis is linked to Epstein-Barr virus infection," Reviews in Medical Virology, vol. 16, no. 5, pp. 297-310, 2006.

[33] I. Kang, T. Quan, H. Nolasco et al., "Defective control of latent Epstein-Barr virus infection in systemic lupus erythematosus," Journal of Immunology, vol. 172, no. 2, pp. 1287-1294, 2004.

[34] U. Y. Moon, S. J. Park, S. T. Oh et al., "Patients with systemic lupus erythematosus have abnormally elevated Epstein-Barr virus load in blood," Arthritis Research \& Therapy, vol. 6, no. 4, pp. R295-R302, 2004.

[35] S. F. Yu, H. C. Wu, W. C. Tsai et al., "Detecting EpsteinBarr virus DNA from peripheral blood mononuclear cells in adult patients with systemic lupus erythematosus in Taiwan," Medical Microbiology and Immunology, vol. 194, no. 3, pp. 115-120, 2005.

[36] G. W. Bornkamm, "Epstein-Barr virus and its role in the pathogenesis of Burkitt's lymphoma: an unresolved issue," Seminars in Cancer Biology, vol. 19, no. 6, pp. 351-365, 2009.

[37] K. P. Chang, C. L. Hsu, Y. L. Chang et al., "Complementary serum test of antibodies to Epstein-Barr virus nuclear antigen- 1 and early antigen: a possible alternative for primary screening of nasopharyngeal carcinoma," Oral Oncology, vol. 44, no. 8, pp. 784-792, 2008.

[38] K. Iwatsuki, Z. Xu, M. Takata et al., "The association of latent Epstein-Barr virus infection with hydroa vacciniforme," British Journal of Dermatology, vol. 140, no. 4, pp. 715-721, 1999.

[39] A. El-Guindy, L. Heston, and G. Miller, "A subset of replication proteins enhances origin recognition and lytic replication by the epstein-barr virus ZEBRA protein," PLoS Pathogens, vol. 6, no. 8, Article ID e1001054, 2010.

[40] S. Kenney, J. Kamine, E. H. Holley-Guthrie, J. C. Lin, E. C. Mar, and J. Pagano, "The Epstein-Barr virus (EBV) BZLF1 immediate-early gene product differentially affects latent versus productive EBV promoters," Journal of Virology, vol. 63, no. 4, pp. 1729-1736, 1989.

[41] M. S. Cho, G. Milman, and S. D. Hayward, "A second EpsteinBarr virus early antigen gene in BamHI fragment $M$ encodes a 48- to 50-kilodalton nuclear protein," Journal of Virology, vol. 56, no. 3, pp. 860-866, 1985.

[42] E. A. Holley-Guthrie, E. B. Quinlivan, E. C. Mar, and S. Kenney, "The Epstein-Barr virus (EBV) BMRF1 promoter for early antigen (EA-D) is regulated by the EBV transactivators, BRLF1 and BZLF1, in a cell-specific manner," Journal of Virology, vol. 64, no. 8, pp. 3753-3759, 1990. 
[43] E. B. Quinlivan, E. A. Holley-Guthrie, M. Norris, D. Gutsch, S. L. Bachenheimer, and S. C. Kenney, "Direct BRLF1 binding is required for cooperative BZLF1 /BRLF1 activation of the Epstein-Barr virus early promoter, BMRF1," Nucleic Acids Research, vol. 21, no. 8, pp. 1999-2007, 1993.

[44] Q. Zhang, Y. Hong, D. Dorsky et al., "Functional and physical interactions between the Epstein-Barr virus (EBV) proteins BZLF1 and BMRF1: Effects on EBV transcription and lytic replication," Journal of Virology, vol. 70, no. 8, pp. 5131-5142, 1996.

[45] Q. Zhang, E. Holley-Guthrie, J. Q. Ge, D. Dorsky, and S. Kenney, "The Epstein-Barr virus (EBV) DNA polymerase accessory protein, BMRF1, activates the essential downstream component of the EBV oriLyt," Virology, vol. 230, no. 1, pp. 22-34, 1997.

[46] E. D. Fixman, G. S. Hayward, and S. D. Hayward, "transActing requirements for replication of Epstein-Barr virus oriLyt," Journal of Virology, vol. 66, no. 8, pp. 5030-5039, 1992.

[47] K. Fujii, N. Yokoyama, T. Kiyono et al., "The EpsteinBarr virus Pol catalytic subunit physically interacts with the BBLF4-BSLF1-BBLF2/3 complex," Journal of Virology, vol. 74, no. 6, pp. 2550-2557, 2000.

[48] W. Hammerschmidt and B. Sugden, "Identification and characterization of oriLyt, a lytic origin of DNA replication of Epstein-Barr virus," Cell, vol. 55, no. 3, pp. 427-433, 1988.

[49] G. Liao, F. Y. Wu, and S. D. Hayward, "Interaction with the Epstein-Barr virus helicase targets Zta to DNA replication compartments," Journal of Virology, vol. 75, no. 18, pp. 8792$8802,2001$.

[50] A. Schepers, D. Pich, and W. Hammerschmid, "Activation of oriLyt, the lytic origin of DNA replication of Epstein-Barr virus, by BZLF1," Virology, vol. 220, no. 2, pp. 367-376, 1996.

[51] Y. Zeng, J. Middeldorp, J. J. Madjar, and T. Ooka, "A major DNA binding protein encoded by BALF2 open reading frame of Epstein-Barr Virus (EBV) forms a complex with other EBV DNA-binding proteins: DNAase, EA-D, and DNA polymerase," Virology, vol. 239, no. 2, pp. 285-295, 1997.

[52] D. A. Thorley-Lawson, "Epstein-Barr virus: exploiting the immune system," Nature Reviews Immunology, vol. 1, no. 1, pp. 75-82, 2001.

[53] H. Kanegane, H. Wakiguchi, C. Kanegane, T. Kurashige, and G. Tosato, "Viral interleukin-10 in chronic active EpsteinBarr virus infection," Journal of Infectious Diseases, vol. 176, no. 1, pp. 254-257, 1997.

[54] S. Henderson, D. Huen, M. Rowe, C. Dawson, G. Johnson, and A. Rickinson, "Epstein-Barr virus-coded BHRF1 protein, a viral homologue of $\mathrm{Bcl}-2$, protects human B cells from programmed cell death," Proceedings of the National Academy of Sciences of the United States of America, vol. 90, no. 18, pp. 8479-8483, 1993.

[55] K. M. Wong and A. J. Levine, "Identification and mapping of Epstein-Barr virus early antigens and demonstration of a viral gene activator that functions in trans," Journal of Virology, vol. 60, no. 1, pp. 149-156, 1986.

[56] J. S. Li, B. S. Zhou, G. E. Dutschman, S. P. Grill, R. S. Tan, and Y. C. Cheng, "Association of Epstein-Barr virus early antigen diffuse component and virus-specified DNA polymerase activity," Journal of Virology, vol. 61, no. 9, pp. 2947-2949, 1987.

[57] T. Tsurumi, "Purification and characterization of the DNAbinding activity of the Epstein-Barr virus DNA polymerase accessory protein BMRF1 gene products, as expressed in insect cells by using the baculovirus system," Journal of Virology, vol. 67, no. 3, pp. 1681-1687, 1993.
[58] T. Tsurumi, T. Daikoku, R. Kurachi, and Y. Nishiyama, "Functional interaction between Epstein-Barr virus DNA polymerase catalytic subunit and its accessory subunit in vitro," Journal of Virology, vol. 67, no. 12, pp. 7648-7653, 1993.

[59] T. Daikoku, A. Kudoh, M. Fujita et al., "Architecture of replication compartments formed during Epstein-Barr virus lytic replication," Journal of Virology, vol. 79, no. 6, pp. 34093418, 2005.

[60] S. Nakayama, T. Murata, K. Murayama et al., "EpsteinBarr virus polymerase processivity factor enhances BALF2 promoter transcription as a coactivator for the BZLF1 immediate-early protein," Journal of Biological Chemistry, vol. 284, no. 32, pp. 21557-21568, 2009.

[61] Q. Zhang, E. Holley-Guthrie, D. Dorsky, and S. Kenney, "Identification of transactivator and nuclear localization domains in the Epstein-Barr virus DNA polymerase accessory protein, BMRF1," Journal of General Virology, vol. 80, no. 1, pp. 69-74, 1999.

[62] A. Kiehl and D. I. Dorsky, "Bipartite DNA-binding region of the Epstein-Barr virus BMRF1 product essential for DNA polymerase accessory function," Journal of Virology, vol. 69, no. 3, pp. 1669-1677, 1995.

[63] B. Neuhierl, R. Feederle, W. Hammerschmidt, and H. J. Delecluse, "Glycoprotein gp110 of Epstein-Barr virus determines viral tropism and efficiency of infection," Proceedings of the National Academy of Sciences of the United States of America, vol. 99, no. 23, pp. 15036-15041, 2002.

[64] B. W. Henson, E. M. Perkins, J. E. Cothran, and P. Desai, "Self-assembly of Epstein-Barr virus capsids," Journal of Virology, vol. 83, no. 8, pp. 3877-3890, 2009.

[65] A. H. Draborg, J. M. Jørgensen, H. Müller et al., "EpsteinBarr virus diffuse early antigen directed immunoglobulin A antibodies in systemic lupus erythematosus patients," Scandinavian Journal of Rheumatology. In press.

[66] G. J. Babcock, D. Hochberg, and D. A. Thorley-Lawson, "The expression pattern of Epstein-Barr virus latent genes in vivo is dependent upon the differentiation stage of the infected $\mathrm{B}$ cell," Immunity, vol. 13, no. 4, pp. 497-506, 2000.

[67] B. Adler, E. Schaadt, B. Kempkes, U. Zimber-Strobl, B. Baier, and G. W. Bornkamm, "Control of Epstein-Barr virus reactivation by activated $\mathrm{CD} 40$ and viral latent membrane protein 1," Proceedings of the National Academy of Sciences of the United States of America, vol. 99, no. 1, pp. 437-442, 2002.

[68] J. Levitskaya, A. Sharipo, A. Leonchiks, A. Ciechanover, and M. G. Masucci, "Inhibition of ubiquitin/proteasomedependent protein degradation by the Gly-Ala repeat domain of the Epstein-Barr virus nuclear antigen 1," Proceedings of the National Academy of Sciences of the United States of America, vol. 94, no. 23, pp. 12616-12621, 1997.

[69] L. L. Laichalk and D. A. Thorley-Lawson, "Terminal differentiation into plasma cells initiates the replicative cycle of Epstein-Barr virus in vivo," Journal of Virology, vol. 79, no. 2, pp. 1296-1307, 2005.

[70] N. M. Steven, N. E. Annels, A. Kumar, A. M. Leese, M. G. Kurilla, and A. B. Rickinson, "Immediate early and early lytic cycle proteins are frequent targets of the Epstein-Barr virusinduced cytotoxic T cell response," Journal of Experimental Medicine, vol. 185, no. 9, pp. 1605-1617, 1997.

[71] J. Setsuda, J. Teruya-Feldstein, N. L. Harris et al., "Interleukin-18, interferon- $\gamma$, IP-10, and Mig expression in Epstein- Barr virus-induced infectious mononucleosis and posttransplant lymphoproliferative disease," American Journal of Pathology, vol. 155, no. 1, pp. 257-265, 1999. 
[72] K. Iwatsuki, T. Yamamoto, K. Tsuji et al., "A spectrum of clinical manifestations caused by host immune responses against Epstein-Barr virus infections," Acta Medica Okayama, vol. 58, no. 4, pp. 169-180, 2004.

[73] J. F. Jones and S. E. Straus, "Chronic Epstein-Barr virus infection,” Annual Review of Medicine, vol. 38, pp. 195-209, 1987.

[74] T. Ooka, M. De Turenne-Tessier, and M. C. Stolzenberg, "Relationship between antibody production to Epstein-Barr virus (EBV) early antigens and various EBV-related diseases," Springer Seminars in Immunopathology, vol. 13, no. 2, pp. 233-247, 1991.

[75] S. Bhaduri-McIntosh, M. L. Landry, S. Nikiforow, M. Rotenberg, A. El-Guindy, and G. Miller, "Serum IgA antibodies to Epstein-Barr virus (EBV) early lytic antigens are present in primary EBV infection," Journal of Infectious Diseases, vol. 195, no. 4, pp. 483-492, 2007.

[76] J. A. James, K. M. Kaufman, A. D. Farris, E. Taylor-Albert, T. J. A. Lehman, and J. B. Harley, "An increased prevalence of Epstein-Barr virus infection in young patients suggests a possible etiology for systemic lupus erythematosus," Journal of Clinical Investigation, vol. 100, no. 12, pp. 3019-3026, 1997.

[77] M. T. McClain, B. D. Poole, B. F. Bruner, K. M. Kaufman, J. B. Harley, and J. A. James, "An altered immune response to Epstein-Barr nuclear antigen 1 in pediatric systemic lupus erythematosus," Arthritis and Rheumatism, vol. 54, no. 1, pp. 360-368, 2006.

[78] C. Garzelli, M. Manunta, M. Incaprera, A. Bazzichi, P. G. Conaldi, and G. Falcone, "Antibodies to histones in infectious mononucleosis," Immunology Letters, vol. 32, no. 2, pp. 111116, 1992.

[79] S. P. Halbert and M. Anken, "Auto-antibodies in infectious mononucleosis, as determined by ELISA," International Archives of Allergy and Applied Immunology, vol. 69, no. 3, pp. 257-261, 1982.

[80] J. J. Y. Lu, D. Y. Chen, C. W. Hsieh, J. L. Lan, F. J. Lin, and S. H. Lin, "Association of Epstein-Barr virus infection with systemic lupus erythematosus in Taiwan," Lupus, vol. 16, no. 3, pp. 168-175, 2007.

[81] B. D. Poole, A. K. Templeton, J. M. Guthridge, E. J. Brown, J. B. Harley, and J. A. James, "Aberrant Epstein-Barr viral infection in systemic lupus erythematosus," Autoimmunity Reviews, vol. 8, no. 4, pp. 337-342, 2009.

[82] Y. Berkun, G. Zandman-Goddard, O. Barzilai et al., "Infectious antibodies in systemic lupus erythematosus patients," Lupus, vol. 18, no. 13, pp. 1129-1135, 2009.

[83] D. Y. Chen, Y. M. Chen, J. L. Lan et al., "Polymyositis/dermatomyositis and nasopharyngeal carcinoma: the Epstein-Barr virus connection?" Journal of Clinical Virology, vol. 49, no. 4, pp. 290-295, 2010.

[84] M. L. Huggins, I. Todd, and R. J. Powell, "Reactivation of Epstein-Barr virus in patients with systemic lupus erythematosus," Rheumatology International, vol. 25, no. 3, pp. 183187, 2005.

[85] P. Stratta, C. Canavese, G. Ciccone et al., "Correlation between cytomegalovirus infection and Raynaud's phenomenon in lupus nephritis," Nephron, vol. 82, no. 2, pp. 145-154, 1999.

[86] C. J. Chen, K. H. Lin, S. C. Lin et al., "High prevalence of immunoglobulin A antibody against Epstein-Barr virus capsid antigen in adult patients with lupus with disease flare: case control studies," Journal of Rheumatology, vol. 32, no. 1, pp. 44-47, 2005.
[87] C. G. Parks, G. S. Cooper, L. L. Hudson et al., "Association of Epstein-Barr virus with systemic lupus erythematosus: effect modification by race, age, and cytotoxic T lymphocyteassociated antigen 4 genotype," Arthritis and Rheumatism, vol. 52, no. 4, pp. 1148-1159, 2005.

[88] B. A. Esen, G. YIlmaz, S. Uzun et al., "Serologic response to Epstein-Barr virus antigens in patients with systemic lupus erythematosus: a controlled study," Rheumatology International, vol. 32, no. 1, pp. 79-83, 2012.

[89] G. Zandman-Goddard, Y. Berkun, O. Barzilai et al., "Exposure to Epstein-Barr virus infection is associated with mild systemic lupus erythematosus disease," Annals of the New York Academy of Sciences, vol. 1173, pp. 658-663, 2009.

[90] C. S. Lau, K. Y. Yuen, K. H. Chan, and R. W. S. Wong, "Lack of evidence of active lytic replication of EpsteinBarr and cytomegaloviruses in patients with systemic lupus erythematosus," Chinese Medical Journal, vol. 111, no. 7, pp. 660-665, 1998.

[91] A. P. Grammatikos and G. C. Tsokos, "Immunodeficiency and autoimmunity: lessons from systemic lupus erythematosus," Trends in Molecular Medicine, vol. 18, no. 2, pp. 101108, 2012.

[92] A. P. F. Mantovani, M. P. Monclaro, and T. L. Skare, "Prevalence of IgA deficiency in adult systemic lupus erythematosus and the study of the association with its clinical and autoantibody profiles," Revista Brasileira de Reumatologia, vol. 50, no. 3, pp. 273-282, 2010.

[93] B. D. Poole, R. H. Scofield, J. B. Harley, and J. A. James, "Epstein-Barr virus and molecular mimicry in systemic lupus erythematosus," Autoimmunity, vol. 39, no. 1, pp. 63-70, 2006.

[94] J. B. Harley and J. A. James, "Epstein-Barr virus infection induces lupus autoimmunity," Bulletin of the NYU Hospital for Joint Diseases, vol. 64, no. 1-2, pp. 45-50, 2006.

[95] B. D. Poole, T. Gross, S. Maier, J. B. Harley, and J. A. James, "Lupus-like autoantibody development in rabbits and mice after immunization with EBNA-1 fragments," Journal of Autoimmunity, vol. 31, no. 4, pp. 362-371, 2008.

[96] B. R. Berner, M. Tary-Lehmann, N. L. Yonkers, A. D. Askari, P. V. Lehmann, and D. D. Anthony, "Phenotypic and functional analysis of EBV-specific memory CD8 cells in SLE," Cellular Immunology, vol. 235, no. 1, pp. 29-38, 2005.

[97] I. Sekigawa, M. Nawata, N. Seta, M. Yamada, N. Iida, and H. Hashimoto, "Cytomegalovirus infection in patients with systemic lupus erythematosus," Clinical and Experimental Rheumatology, vol. 20, no. 4, pp. 559-564, 2002.

[98] M. Pavlovic, A. Kats, M. Cavallo, and Y. Shoenfeld, "Clinical and molecular evidence for association of SLE with parvovirus B19," Lupus, vol. 19, no. 7, pp. 783-792, 2010.

[99] E. Balada, M. Vilardell-Tarrés, and J. Ordi-Ros, "Implication of human endogenous retroviruses in the development of autoimmune diseases," International Reviews of Immunology, vol. 29, no. 4, pp. 351-370, 2010.

[100] A. Doria, M. Canova, M. Tonon et al., "Infections as triggers and complications of systemic lupus erythematosus," Autoimmunity Reviews, vol. 8, no. 1, pp. 24-28, 2008. 


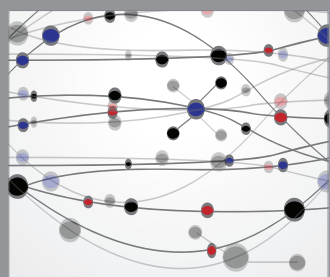

The Scientific World Journal
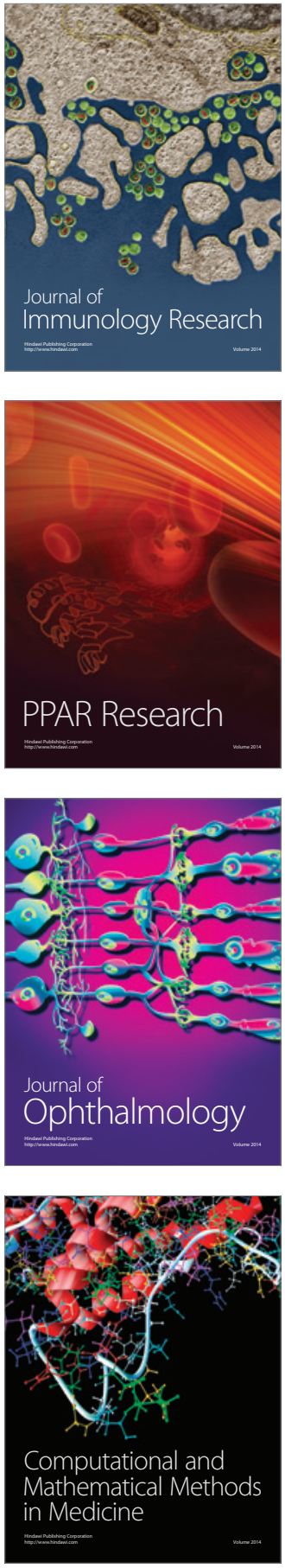

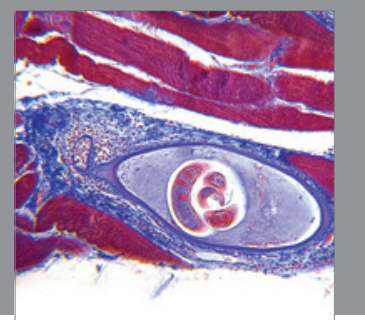

Gastroenterology

Research and Practice
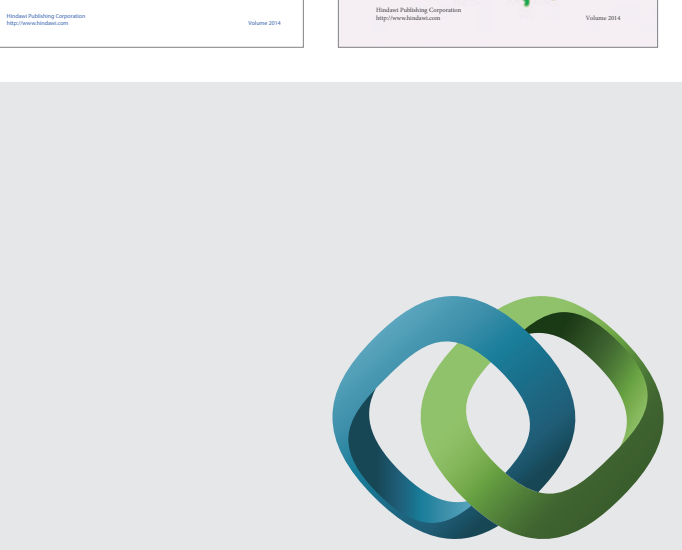

\section{Hindawi}

Submit your manuscripts at

http://www.hindawi.com
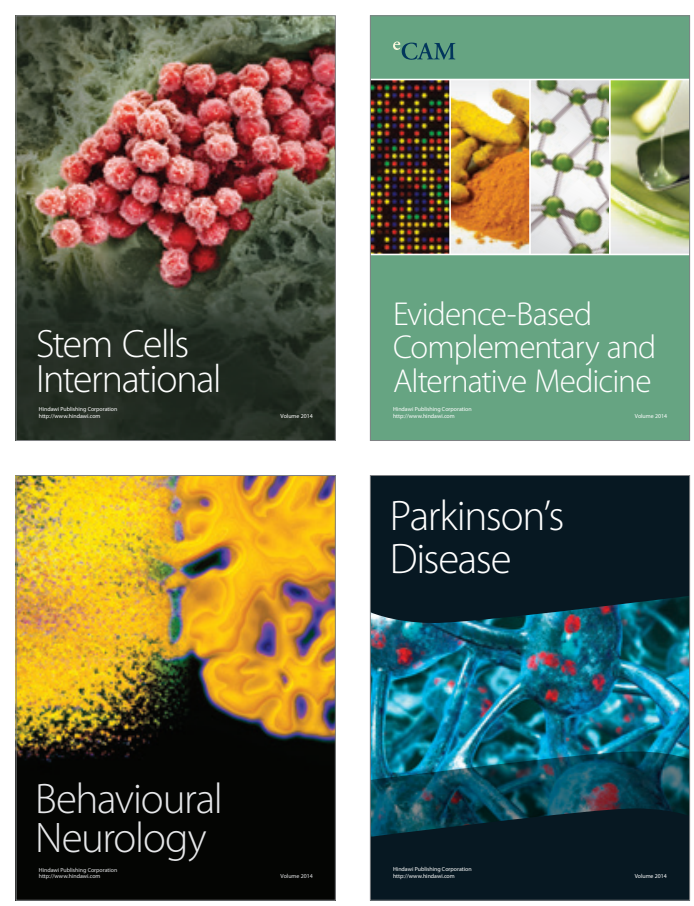

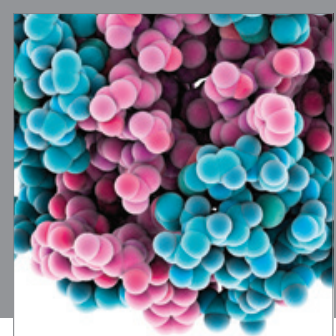

Journal of
Diabetes Research

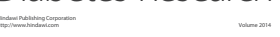

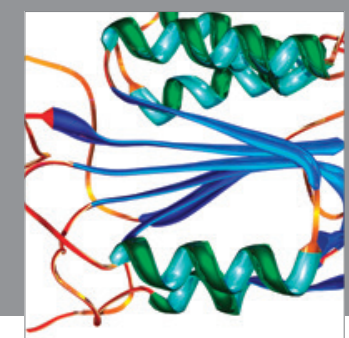

Disease Markers
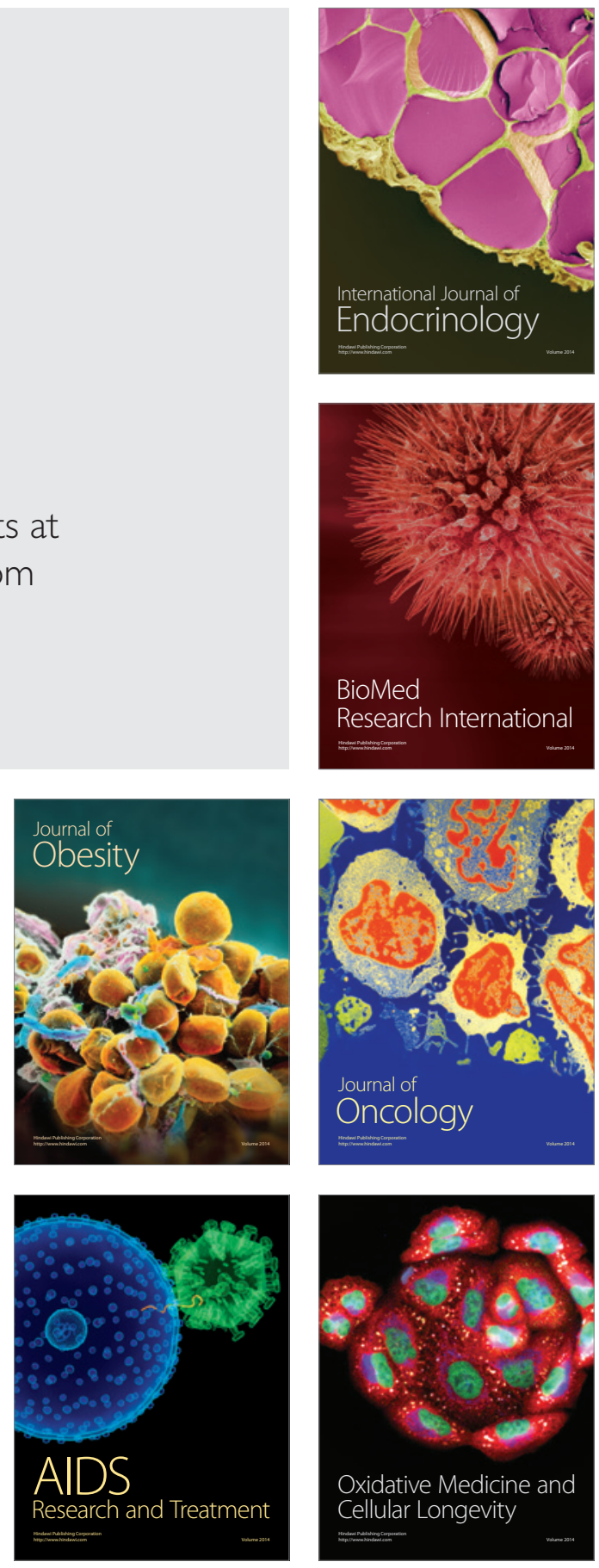